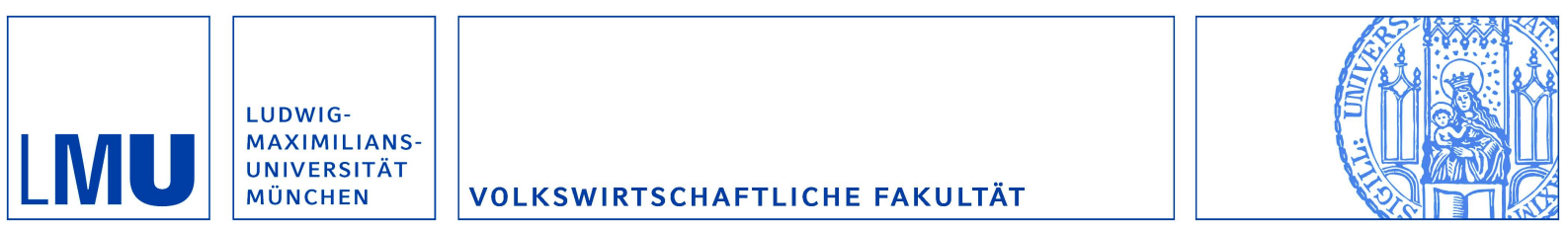

Lührmann, Melanie; Serra-Garcia, Marta und Winter, Joachim:

Teaching teenagers in finance: does it work?

Munich Discussion Paper No. 2012-24

Department of Economics

University of Munich

Volkswirtschaftliche Fakultät

Ludwig-Maximilians-Universität München

Online at https://doi.org/10.5282/ubm/epub. 14101 


\title{
Teaching teenagers in finance: does it work?*
}

\author{
Melanie Lührmann, Marta Serra-Garcia ${ }^{\ddagger}$ and Joachim Winter ${ }^{\S}$
}

December 2013

\begin{abstract}
Many initiatives worldwide aim at improving financial literacy through targeted education programs, yet there is little evidence regarding their effectiveness. We examine the impact of a short financial education program on teenagers in German high schools. Our findings reveal that the training program significantly increases teenagers' interest in financial matters and their financial knowledge, especially their ability to properly assess the riskiness of assets. Behaviorally, we observe a decrease in the prevalence of self-reported impulse purchases, but at the same time find no evidence of a significant increase in savings. Our data reveals strong gender differences already before adulthood: Girls show less interest in, and self-assessed knowledge of, financial matters, and are less likely to save.
\end{abstract}

\footnotetext{
*We would like to thank the team of My Finance Coach, Munich, for supporting the survey fieldwork, the "Gleichstellungsfonds" of the University of Munich for financial support, and Johanna Sophie Quis for excellent research assistance. We would also like to thank Davide Cantoni, Philip Neary, Dan Houser, and the audiences at the Conference on "Financial Literacy, Saving and Retirement in an Ageing Society" at Collegio Carlo Alberto, Turin, the 2013 Annual Conferences of the Royal Economic Society and the Verein für Socialpolitik, and at seminars at the Deutsche Bundesbank, Frankfurt, RAND, Santa Monica, and the University of Düsseldorf for their comments and suggestions.

${ }^{\dagger}$ Institute for Fiscal Studies, London; Royal Holloway, University of London; and Munich Center for the Economics of Aging (MEA). E-mail: melanie.luhrmann@rhul.ac.uk

${ }^{\ddagger}$ Rady School of Management, University of California, San Diego. E-mail: mserragarcia@ucsd.edu

${ }^{\S}$ University of Munich and Munich Center for the Economics of Aging (MEA). Corresponding author. E-mail: winter@lmu.de
} 


\section{Introduction}

Insufficient savings and bad financial decision-making are major concerns in the face of increasingly complex financial markets and larger reliance on individual financial provision for old age. While these concerns have been raised for decades (see, inter alia, Engen, Gale and Scholz, 1996; Skinner, 2007), recent research has shown that households' actual decision processes face many limitations and poor decisions occur frequently. For example, some individuals repeatedly pay expensive overdraft fees on their credit cards (Stango and Zinman, 2009a), they seem to be taken advantage of by brokers when choosing a mortgage (Woodward and Hall, 2011), a large portion feel overburdened with debt (e.g., Lusardi and Tufano, 2009).

One explanation for inadequate financial decisions is a lack of financial knowledge. Lusardi et al. (2010) find that "fewer than one-third of young adults possess basic knowledge of interest rates, inflation and risk diversification." Literacy levels are low among the young and persist over the life cycle (Lusardi and Mitchell, 2008), and measures of financial literacy are generally correlated with household wealth (van Rooij et al., 2012). Christelis et al. (2010) highlight the impeding role of information constraints in portfolio choice, and Jappelli and Padula (2013) stress the effects of financial literacy on savings decisions. Given the concern that many individuals lack the ability to make solid financial decisions, Lusardi and Mitchell (2007a, b) and Hastings et al. (2012) call for systematic efforts to increase financial literacy. While several policy interventions aimed at increasing financial literacy have been proposed and implemented, there is to date little evidence on whether and how financial literacy increases through training (see Hastings et al., 2012).

In this paper, we assess the effects of a short financial education program on financial literacy and financial decision-making among German high school teenagers, with a particular focus on teenagers who come, on average, from families of low socio-economic status (SES). We study a financial education program for teenagers rather than adults for three reasons: First, cognitive abilities peak in young adulthood so that learning efficiency is likely to be highest at younger ages (Heckman, 2006). Secondly, attitudes towards financial decisions, such as shopping and saving, are already important at young ages and have large 
cumulative effects over the life cycle. This is quantified in Lusardi et al. (2013) who study financial knowledge accumulation in a dynamic life cycle model. They find that over half of lifetime wealth inequality can be attributed to heterogeneity in financial knowledge in early adulthood. They conclude that "educational efforts to enhance financial savvy early in the life cycle so as to produce one percentage point excess return per year would be valued highly by people in all educational groups." Third, keeping program scalability in mind, integration of financial education into the school curriculum is attractive: coverage and outreach can be achieved across all population groups as attendance is mandatory (Hastings et al., 2012). We target schools with teenagers from low-SES families since deficiencies in financial literacy are particularly concentrated in these low-SES strata of the population (e.g., Lusardi and Mitchell, 2008; Jappelli, 2010).

The financial education program we examine consists of three 90-minute training modules, focused on shopping, planning, and saving. The module on shopping provides information about the aims of advertising and raises awareness about impulsive vs. deliberated shopping decisions. The module on planning discusses the difference between one-off and repeated costs and provides students with budgeting tools to help them reach their financial goals. Finally, the training on saving discusses the characteristics of different financial products, focusing on the trade-off between risk, liquidity, and return.

The program is offered to by a non-profit organization in Germany (henceforth, the "provider"). The modules are typically administered during a week in normal class hours by volunteers who visit the class, and participation is compulsory. Hence, our setting rules out self-selection of students. ${ }^{1}$ In our analysis of the effects of the training modules, we need to distinguish treated classes and those in a control group. Allocation to treatment and control occurs at the school level, avoiding spillover effects, and is determined by scheduling restrictions. Towards the end of the school year, teachers who had previously shown an interest in the program were asked whether they would have time in their schedule for the financial education program during the remainder of the school year. If teachers and volunteers were available, the school was allocated to the treatment group. Otherwise,

\footnotetext{
${ }^{1}$ The fact that trainings are compulsory is important, given the presence of self-selection from more patient individuals into financial literacy trainings offered to adults (Meier and Sprenger, 2013).
} 
trainings were scheduled for the next school year, and the classes belong to the control group. To control for potential biases arising from the non-random assignment process, we implemented a before-after design by fielding two surveys in each group, which allows us to use a difference-in-differences approach. This allows us to remove any systematic differences between treatment and control, as measured before treatment. When comparing students on an array of background characteristics, including numeracy and cognitive ability, as well as outcome variables (financial interest, knowledge and behavior) across treatment and control classes at baseline, we find no significant differences. Moreover, the potential for selection at the class/school level into the treatment group is mitigated by the fact that the financial training modules we study are provided by outsiders (volunteers of the provider), and not by the teachers themselves. Teachers did not examine students about the trainings nor were they evaluated themselves. Further, our results remain robust across different robustness checks.

At baseline, teenagers' interest in finance and knowledge is limited. More than $38 \%$ of the surveyed students have no interest in financial matters and only $21 \%$ of students stating that their knowledge is good or very good. Probing into their knowledge using factual questions, we find mixed results: Many students can identify the least risky financial product but over a quarter $(26 \%)$ believe that smartphones do not have repeated costs. When it comes to behaviors, almost half the students report that they shop impulsively. At the same time, about $60 \%$ report to have enough money left at the end of the week and save. Hence, while their shopping habits appear to reflect some lack of self-control, students do not seem to be tightly constrained in their budgets (which mainly stem from pocket money).

Our analysis reveals that the relatively short financial education program significantly increases both knowledge of, and interest in, financial matters. Interest in financial matters increases by about 20\%, and the difference is strongly statistically significant. Similarly, self-assessed financial knowledge increases by about 21\%. Students do not only feel more informed, their financial knowledge improves with the training. In particular, the strongest increase is observed in the percentage of students who assess the riskiness of assets correctly.

We observe a significant change in self-reported shopping behavior. The likelihood that a student identifies herself as an impulse buyer decreases with the training. Impulse 
decisions, especially impulse purchases (Vohs and Faber, 2007), have been widely interpreted in psychology and economics as a deviation from rational behavior. They are viewed as the result of time-inconsistent preferences (Frederick et al., 2002), which are in turn related to willpower depletion. ${ }^{2}$ Changing impulse purchases is also important since shopping is one of the main dimensions along which teenagers make financial choices, i.e., they receive pocket money from their parents and then face the decision of what to do with this money. On the other hand, we do not observe a change in students' reported savings. This suggests that the decrease in impulse shopping is not driven by a demand effect, as self-reported savings would presumably be subject to the same demand effect.

We find strong gender differences already at these young ages of 13 to 15 years, controlling for numeracy and cognition. Gender differences are present in all dimensions of financial matters: financial knowledge, motivation, and behavior. Girls are less likely to be interested in financial matters to start with, and their self-assessed knowledge is also lower. The latter may be partly explained by boys' overconfidence (gender differences in overconfidence are known to exist among adults, e.g. Barber and Odean, 2001). Girls are also less likely to save and, consistent with this, more likely to have just enough money to make ends meet at the end of the month. Similar gender differences have been found, especially for financial literacy, among adults (e.g., Lusardi and Mitchell, 2008; Almenberg and Dreber, 2012; Bucher-Koenen et al., 2012). The fact that we find them already at such young ages suggests that other factors than those associated with the gender gap among adults (e.g., differential responsibility for managing household finances or the wage gap) must be at play as well.

Our paper is among the first to assess the impact of a financial education program on the financial knowledge and behaviors of teenagers. A large literature has focused on adults and small entrepreneurs and found mixed results, (e.g., Bruhn and Zia, 2011; Cole et al., 2011; Carpena et al., 2011; Collins, 2012; Drexler et al., 2010; Gibson et al., 2012; and Karlan and Valdivia, 2011). A growing literature focuses on teenagers and the impact

\footnotetext{
${ }^{2}$ Psychologists view the individual as struggling between desire and restraint and find that the repeated exertion of effort leads to willpower depletion (for a survey of the related literature in economics, see Bucciol et al., 2010). Succumbing to temptation thus may result from lack of self-control, which has been shown to be particularly prevalent among teenagers and decreasing in age (Mischel and Metzner 1962; Mischel and Mischel, 1983).
} 
of financial education programs offered in schools. Some studies have focused on nationwide programs, using the timing of implementation at the state level to identify impacts (Bernheim et al., 2001; Cole et al., 2012). These studies also find mixed results. An event study of the introduction of financial education to high-school curriculums in the U.S. by Brown et al. (2013) provides evidence of significant favorable effects of financial education on youth indebtedness, reducing the likelihood of having a credit report, the incidence of delinquent accounts, and the amount of debt held.

A couple of recent studies focus on the impact of different programs on knowledge (Walstad et al., 2010, Bechetti and Pisani, 2012) or behavior on a virtual platform (Carlin and Robinson, 2012). An important contribution of our paper is that we measure knowledge and elicit behavior through a survey, and hence provide a more complete analysis of the impact of financial education. We also collect a large set of background characteristics, including numeracy (math grade) and cognitive ability (Raven's progressive matrices). Hence, we are able to control for students' ability when assessing the impact of the training. As most of the literature, we measure short-run effects. However, our finding of changes in the attitude towards financial matters and in shopping behavior suggests a more fundamental effect on teenagers' mentality, which may potentially have long-run impacts as well.

The remainder of this paper is structured as follows. We describe the context of the study, the training units offered by the financial training provider and the design of our study in Section 2. Section 3 presents the results. In Section 4, we summarize our findings and discuss their implications.

\section{Context and study design}

\subsection{The financial literacy initiative}

The financial education program we examine is provided by a non-profit organization, My Finance Coach, which has offered financial education to over 35,000 German high school students, aged mainly between 13 and 15 years, since its startup in October 2010 (see My 
Finance Coach, 2012). ${ }^{3}$ We evaluate the impact of financial education offered through visits of "finance coaches" to schools. These coaches are employees of the (for-profit) firms that sponsor the (non-profit) provider, and they are not compensated for the training they provide to high-school students. They volunteer to conduct several visits of 90 minutes, each of which is dedicated to one of the training modules. The provider offers a set of materials for each module and trains the coaches; hence, visits are standardized.

We evaluate the joint impact of three training modules that are provided to all treated classes: Shopping, Planning, and Saving. The Shopping module deals with acting as an informed consumer in high-school students' own social environment. It focuses on increasing students' awareness of their everyday shopping behavior. It emphasizes the difference between needs and wants, with the objective that students prioritize their purchasing decisions and decrease impulsive purchases. The module also stresses that the objective of advertising is to sell specific products, which is particularly important as advertising tends to be increasingly blended with entertainment. The Planning module discusses the concepts of income and expenses, as well as one-off and repeated costs. It further discusses planning tools to help students reach their financial goals, like buying a motorbike. The last module, Saving, discusses the characteristics of different savings products. It also introduces the "magic triangle", which has risk, return, and liquidity in each corner, illustrating that any financial product implies a trade-off between these three dimensions. The module emphasizes that the adequacy of each product depends on the person's needs. ${ }^{4}$

The high schools in our study pertain to the lower stream of German high schools, in which most students continue with vocational training after graduation (rather than attending college). ${ }^{5}$ Dustmann (2004) shows that there is a strong association between family

\footnotetext{
${ }^{3}$ The provider also trains teachers directly in order to accelerate the program outreach, and organizes extra-curricular activities related to finance, such as a nationwide competition on financial topics. Overall, the provider has reached around 150,000 students through these various channels.

${ }^{4}$ We provide a detailed summary of the content of each training module and how the questions in our survey relate to these in Appendix B. Further detailed information about the training materials can be found at http://en.myfinancecoach.org/, retrieved July 23, 2013.

${ }^{5}$ The school system in Germany has three types of high schools, starting as of age 10. These streams comprise schools in which students pursue vocational training (Hauptschule, Sekundarschule, Mittelschule), combine both vocational training with the option of accessing university later on (Realschule, Gesamtschule, Werkrealschule) or focus on preparation for university studies (Gymnasium). All participating students in our study belong to the first two types of schools.
} 
background (parents' education as well as occupational status) and the level of children's

school stream. Moreover, children in the lower streams also end up having lower income and occupational outcomes as adults. Training programs that focus on lower stream schools hence provide the opportunity to increase financial knowledge among those students who are likely to have the lowest levels of knowledge (e.g. Lusardi and Mitchell, 2008; Jappelli, $2010)$.

\subsection{Study design}

During the spring of 2012, students answered two paper-and-pencil questionnaires: the baseline survey and the follow-up survey. In the treatment classes, the baseline questionnaire was filled in before the three financial education modules started. Directly thereafter, the three training modules took place (mostly, all within in the same week). Approximately three weeks after baseline, the students completed the follow-up questionnaire. Students in the control group completed the questionnaires approximately over the same timespan, with no training in between. Their training was postponed until after the end of the study, sometimes to the next school year, and no finance coach visited the control classes between the two surveys.

Treatment assignment occurred at the school level. Early in the Spring of 2012 (before Easter), teachers that had expressed an interest in participating in the provider's financial literacy trainings were contacted by staff of the provider. They were asked whether they would have time in their schedule to host the three training modules before the summer break - within the next two months - and volunteers were scheduled to act as coaches for the trainings. Scheduling towards the end of the school year (in May and June) is mostly determined by end-of-year examinations which all students have to take, and by one to two practical training weeks during which students visit companies to learn about future potential occupations and are hence out of school. If the class schedule allowed and volunteers were available, the class received the training and was assigned to the treatment group. If time constraints did not allow for the training to be completed before the summer holidays, the training modules were scheduled for the next academic year, and classes were invited to 
participate in our study nevertheless. These classes form the control group. ${ }^{6}$

Importantly, at the time of treatment assignment, both control and treatment teachers were interested in having their students participate in the financial education program, but scheduling restrictions affect its timing and hence allocation of classes to treatment or control. Since scheduling of the training took place in the end of April and in the beginning of May, whether or not the class was available at the same time a volunteer was available was largely pre-determined. Nevertheless, to control for potential biases arising from the non-random assignment process, we take the following steps. First, to control for ex ante differences between the treatment and control groups, our analysis follows a difference-in-differences approach, comparing changes between the two surveys in the treatment and control groups. This also filters out potential survey effects, i.e., any changes in attitudes and knowledge induced by repeated participation in a survey alone. Second, we examine whether there are differences between treatment and control students at baseline and observe basically none, as detailed below. We also examine differences in class characteristics and again observe none. Third, we focus on a financial education program provided by outsiders, i.e. volunteers who work for the sponsors and partners of the provider. Hence, the teacher is not directly involved in the training and is not evaluated in any way for its success. Further, the contents are not examined and graded, as the financial education program is not part of the school curriculum. Fourth, while our focus is on the differences-in-differences approach, we also conducted several robustness checks, including (i) only focusing on the difference between the baseline survey and the follow-up survey and (ii) propensity score matching, with very similar results. ${ }^{7}$

Our sample consists of 32 classes in the treatment group and 15 in the control group. Of the participating classes, some did not manage to have students fill in the follow-up survey before the summer break: 27 classes in the treatment group and 11 in the control group also filled in the follow-up survey. ${ }^{8}$ The total numbers of questionnaires by time period and treatment status are reported in Table $1 .^{9}$ Within participating classes, only students who

\footnotetext{
${ }^{6}$ Nearly all teachers whose classes were eligible for the control group consented to participate in our study.

${ }^{7}$ Results of these robustness checks are provided in Appendix A.

${ }^{8}$ Results remain qualitatively the same if we concentrate only on those classes that filled in the survey at both points in time.

${ }^{9}$ The questionnaires of 6 control-group classes (127 observations) were sent back without indication
} 
had written parental consent could be asked to complete the surveys. Students were handed out informed consent forms by the teacher ahead of time and returned them if their parents decided to consent. Overall, unit response rates within participating classes are high, with an average of $85 \%$ - in spite of absenteeism and the requirement of written parental consent.

Table 1 here

The questionnaire contained questions on financial attitudes, knowledge, behavior and socio-economic characteristics. ${ }^{10}$ A summary is presented in Table 2. Attitude, and generally motivation, plays an important role in the learning behavior of teenagers. Hence, we asked two questions to measure student's attitudes toward finance: one asked the student about his interest in finance and the other about his self-assessed knowledge about finance (interest and knowledge).

Four questions tested the financial knowledge of students. Two of these questions aim at measuring students' awareness of advertising aims, the main knowledge component of the Shopping module. The questions requested students to assess whether advertising wants to sell (advertising 1) and whether it shows what one needs (advertising 2). A further question tests one of the main concepts of the Planning module: whether students have become aware of the difference between one-off and repeated costs with respect to durables (costs). A final question measured whether students had learned about the risk of different financial products, related to the Saving module (risk). These questions were not taken directly from the training content, but adapted to similar situations to examine whether their newly acquired financial knowledge had transferred to broader domains.

Our questions differ from the basic financial literacy questions used by Lusardi et al. (2010) for a number of reasons. First, in 7th and 8th grade students are between 13 and 15 years old, while to date, the basic financial literacy questions have only been asked to adults. Second, the concepts of interest compounding, inflation, and risk diversification are not known to students at these ages ${ }^{11}$ and, most importantly, they are not part of whether the survey was a baseline or follow-up survey and are thus excluded from our empirical analysis.

${ }^{10}$ The survey questions are presented in Appendix B.

${ }^{11}$ For example, in the math classes within our schools students just start to cover basic percentage calculations in the of 7 th grade and finish the topic in 8th grade in most cases. 
the financial education program, which is adapted to teenagers' everyday financial decisionmaking environment: shopping decisions, cost planning for new durables like a smartphone, and simple savings products.

In addition to financial knowledge, the questionnaire contained several questions about students' behavior. The shopping module aims at changing students' purchasing behavior, in particular at reducing impulse purchases. We elicit purchasing behavior and define impulse shoppers as those students who report that they agree much or very much with the following statement: "I buy spontaneously" (impulse shop). ${ }^{12}$ This measure has been found to correlate with actual impulse purchases (Rook and Fischer, 1995). Since the second module of the training deals with budgeting and planning towards a financial goal, students were also asked how they deal with money by the end of the month and about their savings behavior. We measure whether they make ends meet (just enough money), and we ask whether they save (savings) and if so how much (ln(savings)). ${ }^{13}$ Finally, they were asked on what they would spend 100 Euro, within a month, if they had no other sources of income. Several categories were available: savings, food and drinks, clothing, magazines, sweets, going out, computer and internet, music, and others. We focus on the share saved by each from the 100 Euro (hypoth. savings).

Table 2 here

The survey ended by asking students about their gender, age, household characteristics, math grade, and cognitive ability. ${ }^{14}$ We report the average of these measures as well as class and school characteristics in Table 3. The table also reports the $p$-values of the $t$-statistics obtained from an OLS regression of a treatment dummy on each of the background characteristics. We do not observe significant differences in background variables across treatment and control groups. There is only a marginally significant difference in the

\footnotetext{
${ }^{12}$ Responses were given on a Likert scale from 1 (strongly disagree) to 5 (strongly agree), and the dummy variable we use is based on answers 4 or 5 .

${ }^{13}$ We transform reported savings amounts to $\log$ savings, i.e. $s=\ln (S+1)$, where $S$ are reported savings. allowing for observations with zero savings.

${ }^{14}$ We used a subset of 4 questions from the Standard Progressive Matrices by Raven (1989). We chose questions with varying degrees of complexity based on test results in German schools by Heller et al. (1998), in order to capture the distribution of cognitive ability as well as possible with just a few items.
} 
percentage of students with low math grades, whereby treated students are slightly more likely to have lower grades.

Table 3 here

\section{Results}

In this section, we first assess students' attitudes toward financial issues, their financial knowledge, and there financial behavior before the training. In the second part of our empirical analysis, we evaluate whether the training affects these outcomes. The variables that are used throughout this section are those defined in Table 2.

\subsection{Determinants of attitudes, knowledge, and behavior}

Empirical evidence on children's and teenagers' levels of financial literacy in Europe is lacking to date. To fill this gap, PISA, a comparative cross-country survey of pupils' education levels, has been extended in some countries to include financial literacy and numeracy modules in its 2012 edition. However, numerous countries, among them Germany and the UK, are not participating in this extension. We thus provide the first evidence on the socio-economic determinants of financial knowledge of German students, which may help assess whether financial literacy should gain more priority in education policies.

We analyze the determinants of the main outcome variables at baseline by estimating linear regression models specified as

$$
y_{i}=\alpha+\sum_{k} \beta_{k} * z_{k i}+\sum_{j} \beta_{j} * x_{j i}+\gamma * T_{i}+\epsilon_{i},
$$

where outcome $y$ of student $i$ in the baseline survey depends on a set of $k$ individual characteristics $z$ and the characteristics $x$ of the student's class $j$. We also include a dummy for the treatment $T_{i}$ to control for possible differences between treatment and control groups in the baseline survey. We control for the following individual characteristics $z$ : gender, $\log$ of household size, a dummy for whether the student has a single parent, a dummy for whether 
German is spoken at home (migrant background), dummies for ordinal categories of the number of books present in the household (socio-economic background), and dummies for a low math grade ${ }^{15}$ in the past term (numeracy) and for low cognitive score (if the student correctly answered $50 \%$ of the cognition questions). ${ }^{16}$ The school and class characteristics $x$ include the school grade (a dummy which is 1 if the student is in 8th grade, 0 if in 7 th grade), class size, and state (Bundesland) dummies.

Table 4 reveals that, at baseline, students are not interested in financial matters. A majority assess their interest and knowledge in finance as being at a low to medium level (scores 2 and 3 on a 1-5 Likert scale). Their self-assessed knowledge is not high either. Further, a majority answer at least one question about financial knowledge incorrectly. While the rate of mistakes is between $16 \%$ and $25 \%$ in each separate question, students appear to lack good knowledge across a variety of dimensions. Since the questions were about basic financial knowledge, this suggests that financial education programs may have the potential to increase these relatively low knowledge levels.

Table 4 here

Regarding their financial behavior, almost half of the students report to shop on impulse. This indicates that students may not be developing controlled shopping habits. On the other hand, they appear to make ends meet: only a few say that they just have enough money while a majority had money left over, and also a majority report that they save at least some. These findings are consistent with each other. They are also consistent with the fact that students receive sufficient income (from pocket money from their parents and from other irregular sources, as these children are typically too young to work), which seems to allow them to make their own (impulsive) shopping decisions.

Importantly, we do not observe systematic differences in baseline financial knowledge or behavioral measures between the treatment and control groups. We find a statistically

\footnotetext{
${ }^{15}$ We define a low math grade as 4 or worse in the German grade scale ranging from 1 (best) to 6 (worst) where 5 and 6 denote fails. Robustness checks with a cutoff at grade 3 yields similar results.

${ }^{16}$ As a robustness check, we also define the cutoff at $25 \%$ correct answers. The results are very similar. Additionally, we create a cognition index which weights correct answers with the inverse of the proportion of correct answers in our sample to reflect the differing degree of complexity of the questions. Again, the results, which are available on request, do not change qualitatively.
} 
significant and quantitatively important gender difference in attitudes towards finance. As shown in Table 4, girls' financial interest is on average about $10 \%$ lower than that of boys. This gap is even stronger in self-assessed knowledge. This may be partly driven by girls' lower self-confidence (Croson and Gneezy, 2009), as we do not find evidence of a gender gap in tested financial knowledge. There is however a consistent and significant gap in savings behavior. Girls are more likely to have just enough money left at the end of the week, around $10 \%$ say so. In line with this result, they are less likely to save than boys, again about $10 \%$. The difference in savings also appears in the hypothetical savings task where both girls and boys decide how to spend 100 Euro; we return to this finding below.

Existing studies have found that numeracy and cognitive skills are related to financial knowledge and behavior (e.g., Banks and Oldfield, 2007; Banks et al., 2010; Cole et al., 2011). Hence, we examine whether numeracy, measured by students' math grade, and cognitive abilities, measured through a battery of four questions taken from Raven's Standard Progressive Matrices, relate to teenagers' responses in the baseline survey. Students with lower numeracy are more likely to answer the financial knowledge questions incorrectly, especially the question asking whether advertising wants to sell (advertising 1). Their financial behavior reflects somewhat less savings and more impulse shopping, but the effects are not significant. In contrast to numeracy, financial literacy and behavior does not vary much by cognition score. ${ }^{17}$ Students of low socio-economic status, i.e. those living in a household with less than 10 books, are more likely to save and less likely to make impulse purchases. We find no evidence of socio-economics status on self-assessed financial knowledge and little evidence that it is a determinant of knowledge on the purpose of advertising or the assessment of the risk structure of assets.

\subsection{The impact of financial education}

To measure the effects of financial education, we estimate a classical difference-in-difference (DiD) estimator, comparing the change in outcomes between the baseline and follow-up survey across control and treatment group. We control for individual and class characteristics.

\footnotetext{
${ }^{17}$ This is potentially due to the fact that numeracy captures math ability better. As expected, results remain qualitatively the same if only numeracy is included.
} 
Specifically, we estimate a linear regression model,

$$
y_{i t}=\alpha+\beta_{1} * \text { Post }_{t}+\beta_{2} * T_{i}+\beta_{3} * \text { Post }_{t} * T_{i}+\sum_{k} \beta_{k} * z_{k i t}+\sum_{j} \beta_{j} * x_{j i t}+\epsilon_{i t},
$$

where outcome $y$ depends on individual characteristics $z$ and class characteristics $x$, as in section 3.1, and exposure to the financial training T. Post is a dummy which takes the value zero for the baseline survey and 1 for the follow-up. Throughout we conservatively cluster standard errors at the school level, as treatment allocation occurred at this level. ${ }^{18}$

\subsubsection{Attitudes towards finance}

Figure 1 shows a strong increase in financial motivation among the treated students after the training. In the two bottom histograms of Figure 1, we observe that the proportion of responses in the categories "much" and "very much" both increase, so that about $30 \%$ of teenagers state that they are interested in financial matters after the training compared to about $16 \%$ before the training. In contrast, the control group experiences no positive change in these categories. When we use multivariate regression to condition on individual characteristics such as gender, numeracy, cognitive score and socio-economic status, and on class characteristics, this strong effect of the program on students' interest in financial matters persists (Table 5). The difference-in-difference estimate is about 0.57, which corresponds to a $20 \%$ increase in interest in finance through the training. We find no evidence that girls are affected by the training any differently from boys ${ }^{19}$, but they start from a much lower level, so that the lower interest in finance among girls documented for the baseline survey persists after the training.

Figure 1 here

\footnotetext{
${ }^{18}$ The validity of these DiD estimates hinges on reliable measurement of the control group's behavior. Our control group is relatively small with 280 observations compared to 1126 observations in the treatment group, making the measurement of effects in the control group rather noisy. Since we observed no or small differences in the individual characteristics of students before the baseline survey, we also estimate the change in outcomes within the treatment group, but add class-level fixed effects to filter out any class-level heterogeneity. As mentioned above, results remain qualitatively the same when we follow this approach.

${ }^{19}$ The estimation results for heterogeneous treatment effects are available from the authors upon request.
} 
The strong training effect on students' interest in financial matters may be due to three factors: (a) that students' motivation to engage with financial topics and with their own finances increases, and (b) that the training provides them with a definition what financial matters are, or (c) a demand effect. Since our survey is not presented as an evaluation of the program but as a survey conducted by university researchers, and both treatment and control students have participated or will participate in the program, a demand effect only in the treated group seems unlikely. Further, since the training in question does not define the term financial matters precisely, we cannot disentangle between (a) and (b). However, both represent positive training effects. The accumulation of financial literacy is not only enhanced by students' motivation to learn about finances. The first step towards financial literacy is building students' awareness for the fact that they make financial choices on a daily basis, so that they do not view dealing with finances as an alien process.

After the training, we see a similarly strong change in self-reported knowledge as for self-reported interest: While the fraction of those with no or little knowledge about finance decreases to $18 \%$, the fraction of teenagers who feel financially literate increases to 41\%. When controlling for individual and class characteristics, we find an 0.61 increase in self-assessed financial knowledge, corresponding to a $21 \%$ increase in their self-assessed knowledge, as shown in column 2 of Table 5. Again, girls report to know substantially less about financial matters due to their lower baseline level. In addition, we find a weaker treatment effect among girls than boys.

Table 5 here

\subsubsection{Financial knowledge}

Figure 2 reports the proportion of students who answered all financial knowledge questions correctly. While in the control classes, a similar percentage of students answer all questions correctly in the baseline and follow-up survey (38\% and 40\%), we observe an increase in the proportion of students who answer all questions correctly in the treatment group, from $39.5 \%$ to $46.5 \%$. This suggests that financial knowledge increases with the training. This effect is confirmed in Table 6, where controls are added. The likelihood that students answer 
all questions correctly increases (marginally) significantly more among the treated students (see column (1) of Table 6.

Figure 2 here

If we examine each question separately, we observe that the overall improvement in objective knowledge mainly stems from an improvement in the assessment of the risks inherent to different financial products. When asked whether a bank savings account, a house, or company shares are the least risky asset, students shift from real estate to bank account deposits and the percentage giving the correct answer increases by 0.12 percentage points, as shown in column (5) in Table 6.

Table 6 here

Overall, we find strong evidence that the assessment of risk and familiarity with different types of assets increases after the training, and mixed evidence that teenagers become more critical to advertising and more aware of repeated costs in consumer durables.

\subsubsection{Financial behavior}

As Figure 3 shows, the fraction of students who buy on impulse in our sample is high.

Figure 3 here

Figure 3 reveals that the propensity for frequent impulse purchases declines to about $40 \%$ after the financial training. When controlling for individual and class characteristics (see Table 7), we find that the training decreases the proportion of students reporting that they are buying on impulse frequently by 0.1 , corresponding to a $21 \%$ decrease in the fraction of impulse buyers. Hoch und Lowenstein (1991) suggest that cognitive exercises help increase self-control and reduce such time-inconsistent choices. This large change is consistent with their hypothesis that willpower can be increased through training.

Table 7 here 
Table 7 also shows the estimates of the training effect on teenagers' ability to make ends meet and on their savings behavior. We do not find evidence of a decrease in the number of students who just have enough money, nor a significant increase in savings. ${ }^{20}$ On the one hand, this result is not surprising. The module on savings only provides information about the trade-off between risk, liquidity, and return of different savings products, and does not suggest to students that they should save more. Second, the short time span covered by our quasi-experiment, with no more than three weeks between the training and the follow-up survey, makes it unlikely that strong behavioral changes in savings could be observed. ${ }^{21}$ On the other hand, if students adopt new planning habits to save up for a durable good after the financial education program, we would have expected an increase in savings. Such an intention to save could potentially reveal itself in the hypothetical budget allocation task.

In the hypothetical question students allocated a monthly budget of 100 Euros across savings and several consumption categories. Three quarters of students allocate the budget fully across available categories, while allocations do not add up to 100 Euros for $14 \%$ and exceed 100 Euros for $9 \%$ of teenagers. We graph the average allocation of the treatment group before and after the training in Figure 4. The main discernible change in the treatment group is the increase in hypothetical savings from 23 to $26 \%$. However, the control group also increases its savings from 25 to $27 \%$. Hence, the results presented in Column (5) of Table 7 reveal that hypothetical savings do not increase significantly more in the treatment group. Overall, while there is a slight tendency to increase savings in this hypothetical task as well as in actual savings, we do not find strong evidence that the training generated a sizeable increase in savings.

Figure 4 here

\footnotetext{
${ }^{20}$ We also tested $\log$ savings conditional on positive savings, i.e. $s=\log (S)$ if $S>0$, and did not find evidence of increased savings among savers.

${ }^{21}$ Ideally, we would like to measure the behavioral effects of financial education for teenagers by following changes in realized consumption and saving levels over longer time horizons. However, obtaining reliable estimates of saving or consumption using survey methods is generally difficult (e.g., Crossley and Winter, 2012), and measurement problems are even more severe in the context of this study where survey time is very limited.
} 


\section{Discussion and conclusion}

A wide range of studies have shown that adult financial literacy is low. Further, the lack of financial knowledge is correlated with worse financial outcomes: less saving, lower wealth, and lower participation in stock markets. To address these concerns, several initiatives around the world have started to offer financial education in recent years. Yet, there is little consensus or evidence on (i) what constitutes effective financial training and whether low financial literacy levels are due to a lack of information and training or to poor cognitive ability and numeracy skills, and (ii) whether - as is hoped - increasing literacy will lead to better financial outcomes.

In this paper, we evaluate the effect of financial education on teenagers in lower stream schools in Germany. Our study was implemented within a large-scale training program, with compulsory participation of students in treated classes. Our focus has been on the short term effect of training: Does it awake interest in financial matters? Does it increase knowledge? And if so, can we find short-term changes in some dimensions of financial behavior?

Our study reveals that a financial training intervention raises teenagers' interest and self-assessed financial knowledge significantly. This is an expected result, but an important

one. Increasing the interest of teenagers in financial matters is not easy - the right media must be used. Further, their interest is a first step towards increasing their financial literacy and engagement with financial matters in the future. The financial training also increases actual financial knowledge in some dimensions. Teenagers get better at identifying the riskiness of assets, and overall an increase in the number of correct answers is observed.

Students' behavior with respect to shopping also changes: they are less likely to define themselves as impulse buyers. Such a change in buying attitudes is important given concerns that teenagers may purchase durables with considerable running costs without being aware of these costs. The fact that after the training units, teenagers define themselves as less impulsive buyers suggests that their purchases are less likely to be due to a lack of selfcontrol and more the result of some deliberation. The shopping module in the financial training program considered in our study is geared at increasing teenagers' awareness of how they make consumption choices. Hence, the self-reported reduction of impulse purchases may 
be due to improved cognitive reflection that helps increase self-control. The long-run effects of such behavioral interventions on shopping behavior appear to be an important object for future research.

One of the most striking results of our study is that already among teenagers, there are strong gender differences in all dimensions of financial matters - financial knowledge, motivation, and behavior. Girls show lower motivation in financial matters, a lower selfassessed knowledge, and are less likely to save. Yet we do not find evidence that girls and boys are differently affected by the training - with one exception that may be related to self-confidence: self-assessed knowledge increases less for girls than boys, though we find no differences in the treatment effect on their actual knowledge. It should be an important goal for financial education programs to address the gender gap in financial literacy - a worrisome phenomenon which has been documented among adults, and for the first time in this study, also already at these young ages.

Given the lack of effects of many financial education programs among adults, the results of this study suggest that a successful strategy may be to start early on. The program is successful in raising teenagers' interest in financial matters and their subjective knowledge, as well as in changing their attitudes towards buying. These findings thus suggest that even a relatively short financial education program has the potential to help teenagers become more informed and sovereign consumers. 


\section{References}

Almenberg, J. and A. Dreber, 2012. Gender, stock market participation and financial literacy. SSE/EFI Working Paper Series No. 737.

Banks, J. and Z. Oldfield, 2007. Understanding pensions: Cognitive function, numerical ability and retirement saving. Fiscal Studies, 28(2), 143-170.

Banks, J., C. O'Dea and Z. Oldfield, 2010. Cognitive function, numeracy and retirement saving trajectories. Economic Journal, 120(548), F381-F410.

Barber, B.M. and T. Odean, 2001. Boys will be boys: Gender, overconfidence and common stock investment. Quarterly Journal of Economics, 116(1), 261-292.

Becchetti, L. and F. Pisani, 2012. Financial education on secondary school students: The randomized experiment revisited. Aiccon Working Paper No. 98.

Becker, S.O. and A. Ichino, 2002. Estimation of average treatment effects based on propensity scores. Stata Journal, 2(4), 358-377.

Bernheim, B.D., D.M. Garrett and D.M. Maki, 2001. Education and saving: The long-term

effects of high school financial curriculum mandates. Journal of Public Economics, 80(3), $435-465$.

Brown, M., W. van der Klaauw, J. Wen and B. Zafar, 2013. Financial education and the debt behavior of the young. Unpublished manuscript, Federal Reserve Bank of New York.

Bruhn, M. and B. Zia, 2011. Stimulating managerial capital in emerging markets: The impact of business and financial literacy for young entrepreneurs. World Bank Policy Research Working Paper No. 5642.

Bucciol, A., Houser, D. and M. Piovesan, 2010. Willpower in children and adults: a survey of results and economic implications. International Review of Economics, 57, 259-267.

Bucher-Koenen, T. and M. Ziegelmeyer, 2011. Who lost the most? Financial literacy, cognitive abilities, and the financial crisis. European Central Bank Working Paper No. 1299. Carlin, B.I. and D.T. Robinson, 2012. What does financial literacy training teach us? Journal of Economic Education, 43(3), 235-247. 
Carpena, F., Cole, S., Shapiro, J. and B. Zia, 2011. Unpacking the causal chain of financial literacy. World Bank Policy Research Working Paper No. 5798.

Christelis, D., T. Jappelli and M. Padula, 2010. Cognitive abilities and portfolio choice. European Economic Review 54(1), 18-38.

Cohen, A. and L. Einav, 2007. Estimating risk preferences from deductible choice. American Economic Review, 97(3), 745-788.

Cole, S., T. Sampson and B. Zia, 2011. Prices or knowledge? What drives demand for financial services in emerging markets? Journal of Finance, 66(6), 1933-1967.

Cole, S., A. Paulson and G.K. Shastry, 2012. Smart money: The effect of education on financial behavior. Harvard Business School Working Paper No. 09-071.

Collins, J.M., 2012. The impacts of mandatory financial education: Evidence from a randomized field study. Journal of Economic Behavior and Organization, forthcoming.

Crossley, T.C. and J. Winter, 2012. Asking households about expenditures: What have we learned? In: C. Carroll, T.F. Crossley, and J. Sabelhaus, eds., Improving the Measurement of Consumer Expenditures. Chicago and London: Chicago University Press (in press).

Drexler, A., Fischer, G. and A. Schoar, 2010. Keeping it simple: Financial literacy and rules of thumb. CEPR Discussion Paper No. 7994.

Dustmann, C., 2004. Parental background, secondary school track choice and wages. Oxford Economic Papers, 56, 209-230.

Engen, E.M., Gale, W.G. and J.K. Scholz, 1996. The illusory effects of saving incentives on saving. Journal of Economic Perspectives, 10(4), 113-138.

Frederick, S., Loewenstein, G., and T. O’Donoghue, 2002. Time discounting and time preference: A critical review. Journal of Economic Literature, 40, 351-401.

Gibson, J. and D. McKenzie and B. Zia, 2012. The impact of financial literacy training for migrants. World Bank Economic Review, forthcoming.

Hastings, J.S., Madrian, B.C. and W.L. Skimmyhorn, 2012. Financial literacy, financial education and economic outcomes. NBER Working Paper No. 18412. 
Heckmann, J.J., 2006. Skill formation and the economics of investing in disadvantaged children. Science, 312, 1900-1902.

Heller, K.A., Kratzmeier, H. and A. Lengfelder, 1998. Matrizen-Test-Manual, Bd. 1. Ein Handbuch zu den Standard Progressive Matrices von J.C. Raven. Göttingen: BeltzTestgesellschaft.

Hoch, S.J., and G.F. Loewenstein, 1991. Time-inconsistent preferences and consumer selfcontrol. Journal of Consumer Research, 17, 492-507.

Jappelli, T., 2010. Economic literacy: An international comparison. Economic Journal, 120(548), F429-F451.

Jappelli, T. and M. Padula, 2013. Investment in financial literacy and saving decisions. Journal of Banking and Finance, 37, 2779-2792.

Karlan, D. and P. Valdivia, 2011. Teaching entrepreneurship: Impact of business training on microfinance clients and institutions. Review of Economics and Statistics, 93, 510-527.

Lusardi, A. and O.S. Mitchell, 2007a. Baby boomer retirement security: The roles of planning, financial literacy, and housing wealth. Journal of Monetary Economics, 54(1), 205-224.

Lusardi, A. and O.S. Mitchell, 2007b. Financial literacy and retirement preparedness: Evidence and implications for financial education. Business Economics, 42, 35-44.

Lusardi, A. and O.S. Mitchell, 2008. Planning and financial literacy: How do women fare? American Economic Review: Papers 6 Proceedings, 98(2), 413-417.

Lusardi, A. and P. Tufano, 2009. Debt literacy, financial experience and overindebtedness. Working paper, Harvard University.

Lusardi, A., O.S. Mitchell and V. Curto, 2010. Financial literacy among the young. Journal of Consumer Affairs, 44(2), 358-380.

Lusardi, A., P. Michaud and O. S. Mitchell, 2013. Optimal financial knowledge and wealth inequality. NBER Working Paper No. 18669.

Meier, S. and C. Sprenger, 2013. Discounting financial literacy: Time preferences and participation in financial education programs. Journal of Economic Behavior and Organization, 
95, 159-174.

Mischel, W. and R. Metzner, 1962. Preference for delayed reward as a function of age, intelligence, and length of delay interval. Journal of Abnormal and Social Psychology, 64, $425-431$.

Mischel, H.N. and W. Mischel, 1983. The development of children's knowledge of self-control strategies. Child Development, 54, 603-619.

My Finance Coach, 2012. Annual Report, http://www.myfinancecoach.com/

Raven, J., 1989. The Raven Progressive Matrices: A review of national norming studies and ethnic and socioeconomic variations within the United States. Journal of Educational Measurement, 26(1), 1-16.

Skinner, J., 2007. Are you sure you're saving enough for retirement? Journal of Economic Perspectives, 21(3), 59-80.

Stango, V. and J. Zinman, 2009a. What do consumers really pay on their checking and credit card accounts? Explicit, implicit, and avoidable costs. American Economic Review: Papers 8 Proceedings, 99(2), 424-429.

Stango, V. and J. Zinman, 2009b. Exponential growth bias and household finance. Journal of Finance, 64(6), 2807-2849.

van Rooij, M., A. Lusardi and R. Alessie, 2012. Financial literacy, retirement planning, and household wealth. Economic Journal, 122, 449-478.

Vohs, K.D., and R.J. Faber, 2007. Spent resources: self-regulatory resource availability affects impulse buying. Journal of Consumer Research, 33, 537-547.

Walstad, W., K. Rebeck, and R. MacDonald, 2010. The effects of financial education on the financial knowledge of high school students. Journal of Consumer Affairs, 44, 336-357.

Woodward, S.E. and R.E. Hall, 2010. Consumer confusion in the mortgage market: Evidence of less than a perfectly transparent and competitive market. American Economic Review: Papers \& Proceedings, 100(2), 511-515. 


\section{Figures and tables}

Figure 1: Interest in finance, by treatment and control

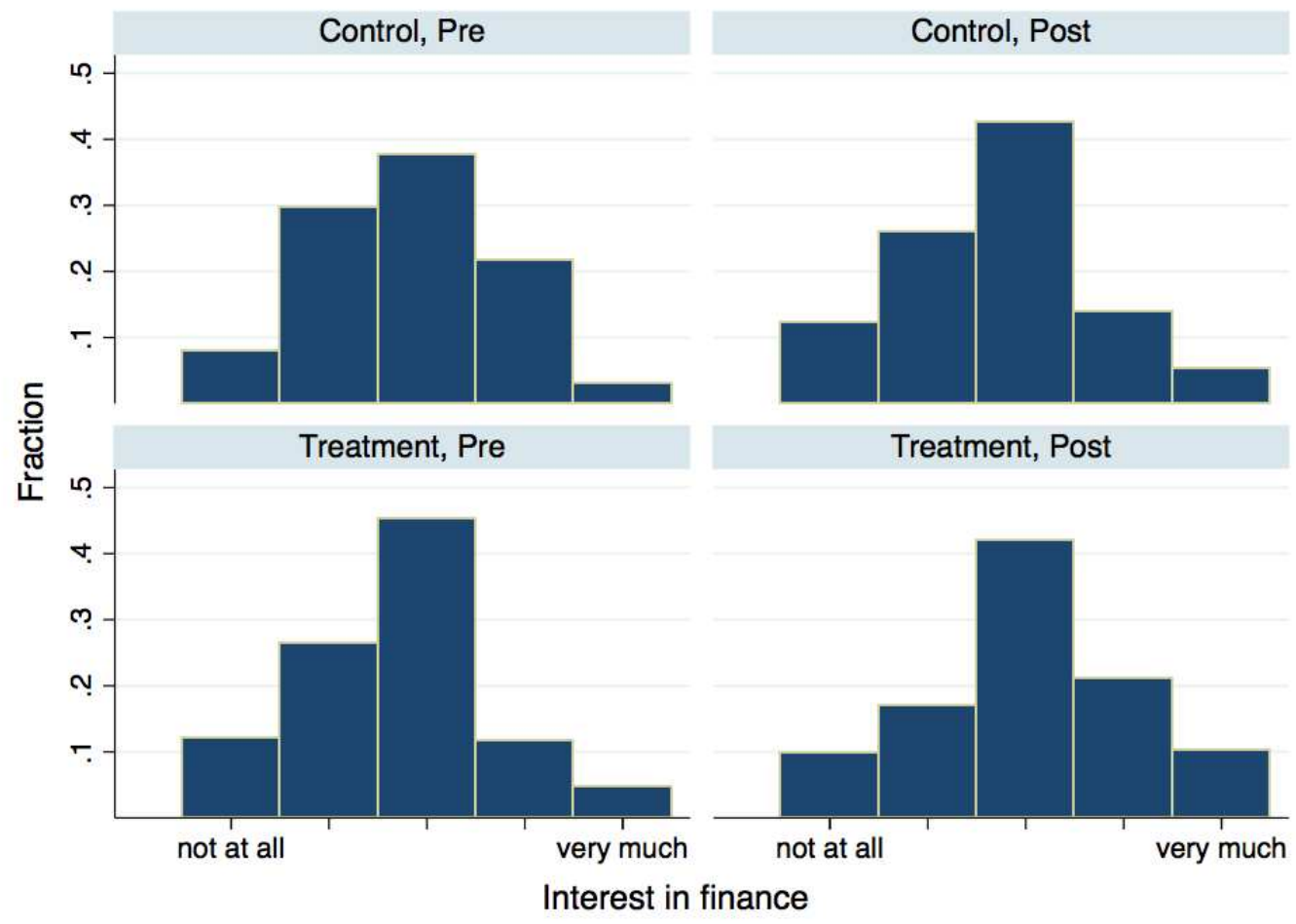

Figure 2: Financial knowledge, by treatment and control

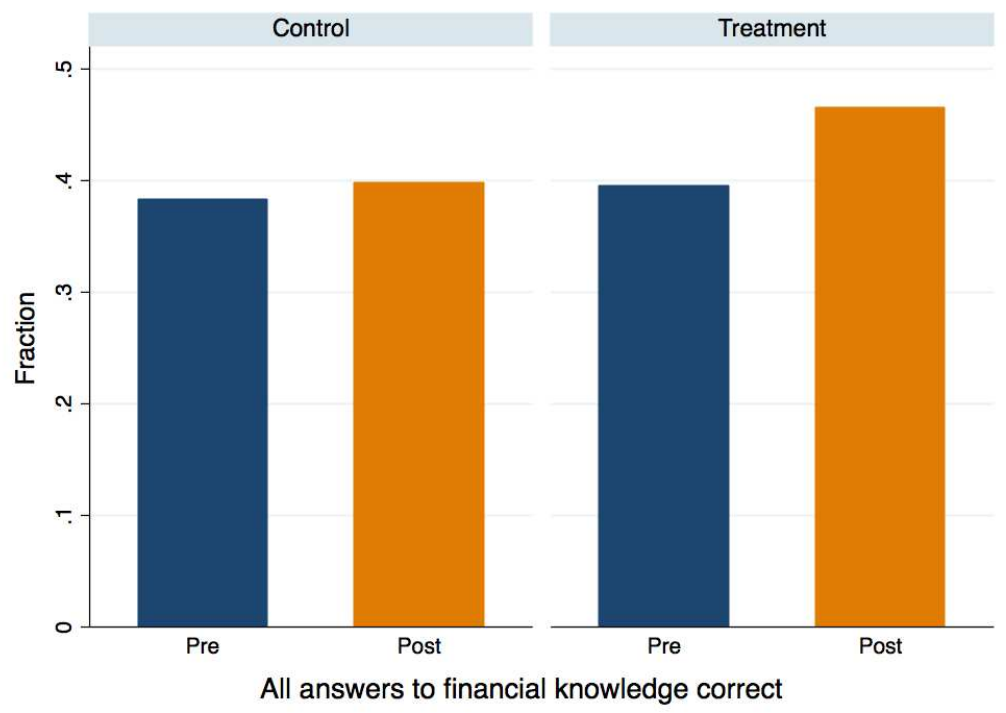


Figure 3: Impulse shopping, by treatment and control

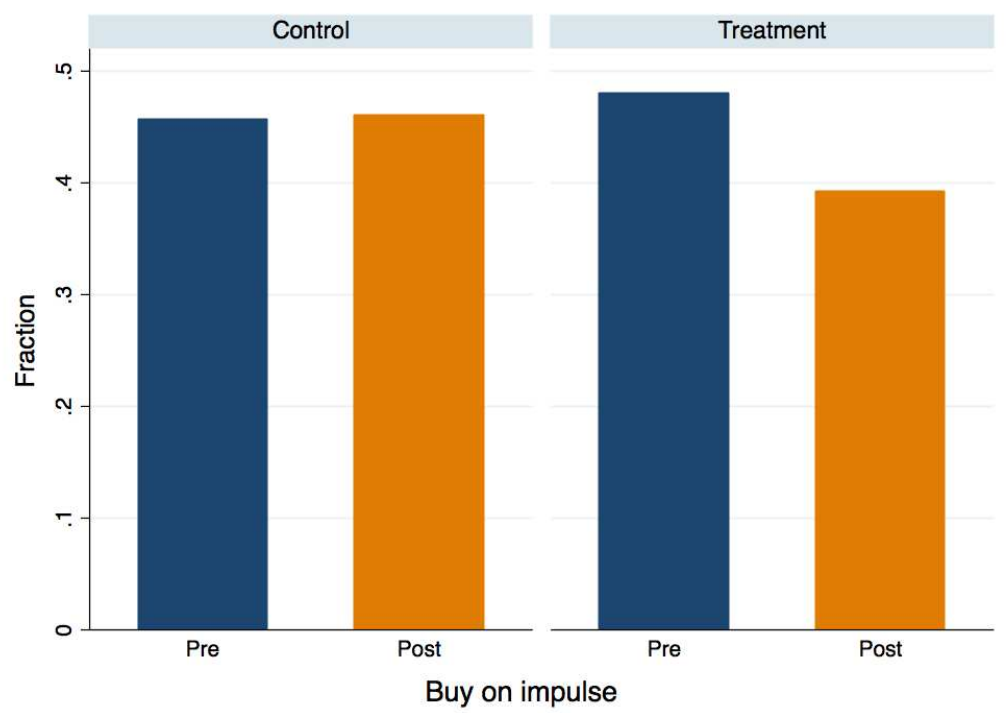

Figure 4: Hypothetical savings-consumption behavior, by treatment and control

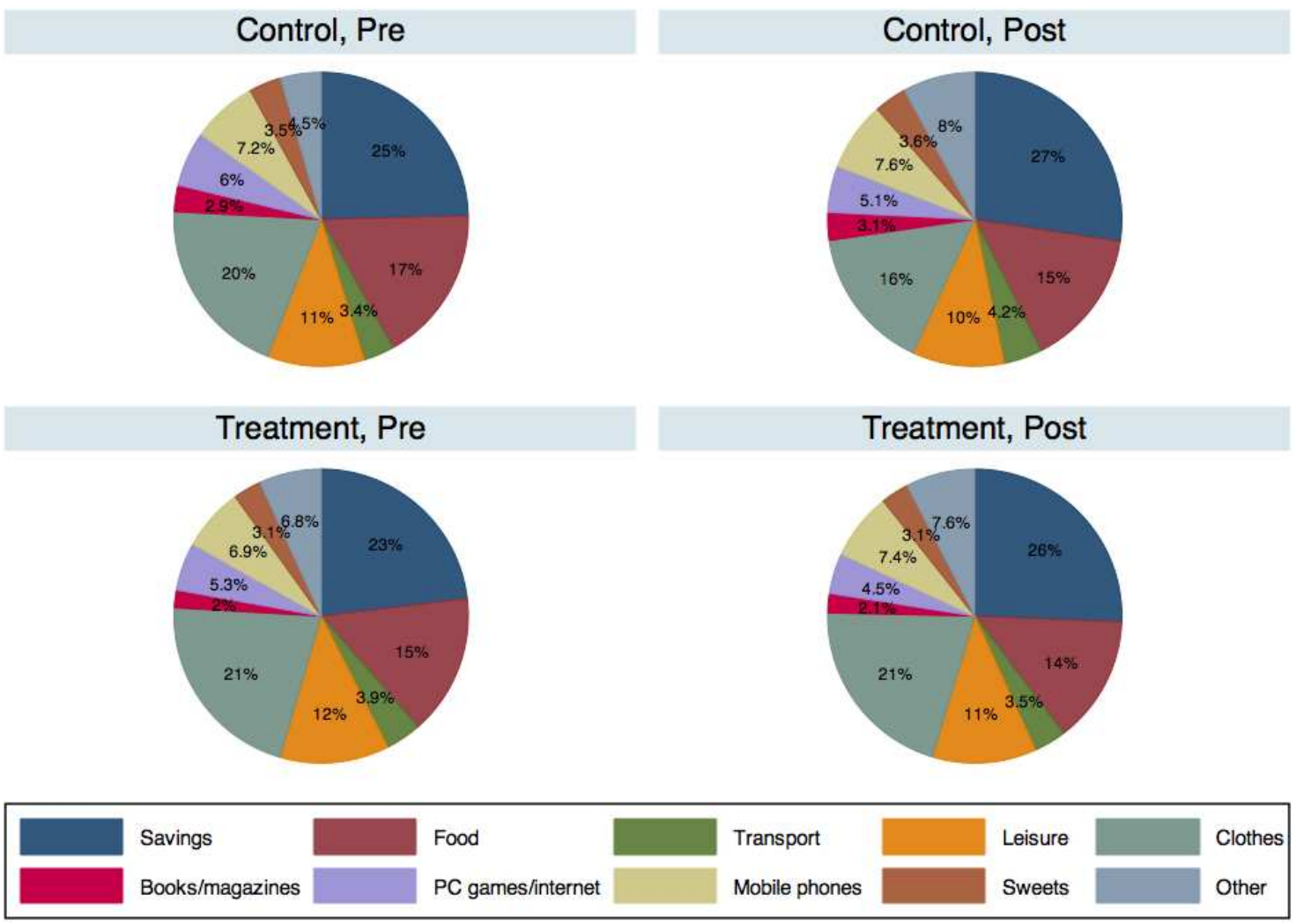


Table 1: Sample size by group and time period

\begin{tabular}{lccc}
\hline \hline & Treatment & Control & \\
\hline Before training period ("pre") & 605 & 165 & \\
After training period ("post") & 521 & 115 & \\
\hline Total & 1126 & 280 & 1406 \\
\hline \hline
\end{tabular}

Table 2: Definition of variables

\begin{tabular}{|c|c|}
\hline Outcome variable & Survey instrument \\
\hline \multicolumn{2}{|c|}{ Attitudes towards finance } \\
\hline Interest & $\begin{array}{l}\text { I am .... Interested in finance. } \\
\text { Answers given on a Likert scale ( } 1=\text { not at all, } 5=\text { very much) }\end{array}$ \\
\hline Knowledge & $\begin{array}{l}\text { I know.... about money and finances. } \\
\text { Answers given on a Likert scale ( } 1=\text { not at all, } 5=\text { very much })\end{array}$ \\
\hline \multicolumn{2}{|c|}{ Financial knowledge } \\
\hline Advertising 1 & $\begin{array}{l}\text { Advertising wants to sell } \\
\text { Correct if answers } 4 \text { or } 5 \text { (agree, strongly agree) }\end{array}$ \\
\hline Advertising 2 & $\begin{array}{l}\text { Advertising wants to show me what I need } \\
\text { Correct if answers } 1 \text { or } 2 \text { (disagree, strongly disagree) }\end{array}$ \\
\hline Costs & $\begin{array}{l}\text { When I buy a smartphone I have repeated costs } \\
\text { Correct if answers } 4 \text { or } 5 \text { (agree, strongly agree) }\end{array}$ \\
\hline Risk & $\begin{array}{l}\text { Which of the following investment options has the least risk? } \\
\text { Correct if least risky asset is identified }\end{array}$ \\
\hline \multicolumn{2}{|l|}{ Financial behavior } \\
\hline Impulse shop & $\begin{array}{l}\text { I buy impulsively } \\
=1 \text { if answers } 4 \text { or } 5 \text { (agree, strongly agree), }=0 \text { otherwise }\end{array}$ \\
\hline Just enough money & $\begin{array}{l}\text { How did you manage your money last week? } \\
\text { Dummy, =1 if "I had just enough money", }=0 \text { otherwise }\end{array}$ \\
\hline Savings & $\begin{array}{l}\text { Do you save? } \\
\text { Dummy, }=1 \text { if "Yes", =0 if "No" }\end{array}$ \\
\hline $\ln$ (savings) & Log of savings amount \\
\hline Hypoth. savings & $\%$ saved in hypothetical savings task \\
\hline
\end{tabular}


Table 3: Background characteristics

\begin{tabular}{lcccc}
\hline \hline & & \multicolumn{3}{c}{ Treatment } \\
& Mean & SD & (p-value) & $\mathrm{N}$ \\
\hline Student characteristics & & & & \\
Girl & $48.4 \%$ & 0.50 & 0.400 & 768 \\
Low math & $32.2 \%$ & 0.47 & 0.069 & 768 \\
Low cognition & $60.2 \%$ & 0.49 & 0.615 & 768 \\
Single parent & $22.4 \%$ & 0.42 & 0.968 & 756 \\
ln(household size) & 1.06 & 0.47 & 0.620 & 756 \\
German & $79.9 \%$ & 0.40 & 0.499 & 767 \\
$0-10$ books at home & $20.7 \%$ & 0.41 & 0.626 & 760 \\
$11-25$ books at home & $25.0 \%$ & 0.43 & 0.736 & 760 \\
$26-100$ books at home & $27.6 \%$ & 0.45 & 0.741 & 760 \\
$101-200$ books at home & $13.9 \%$ & 0.35 & 0.513 & 760 \\
+201 books at home & $12.8 \%$ & 0.33 & 0.251 & 760 \\
& & & & \\
Class and school characteristics & & & & \\
8th grade & $46.2 \%$ & 0.50 & 0.779 & 47 \\
Class size & 22.75 & 5.40 & 0.112 & 47 \\
Vocational training w/ university option & $24.2 \%$ & 0.43 & 0.205 & 47 \\
\hline \hline
\end{tabular}

Note: this table reports the average value of the background characteristics of students, classes and schools. Girl takes value 1 if the student is female, 0 otherwise. Low math takes value 1 if the student obtained a final grade of 4,5 or 6 from a scale of 1 to 6 , where 1 is the highest grade, in the previous year's math class and is 0 otherwise. Low cognition takes value 1 if the student answered correctly less than two or two of the Raven's progressive matrices and is 0 otherwise. Single parent takes value 1 if the student only lives with one parent, 0 otherwise. $\ln$ (household size) is the $\log$ of household size. German takes value 1 if the language spoken at home is German, 0 otherwise. The variables $0-10,11-25,26-100,101-200,201$ + books at home take value 1 if the number of books at home falls in the corresponding range. 8th grade takes value 1 if student is in 8 th grade, 0 if he is in 7 th grade. Class size is the number of students in the class. Vocational training w/ university option takes value 1 if the school belongs to the type of vocational training schools that provide an option to access university. It also takes value 1 if the student is in a class that provides such an option in schools offering both classes without and with the university option. The column Treatment (p-value) reports the p-value of the t-statistic on the coefficient of Treatment, obtained through an OLS regression of each background characteristic on Treatment, estimated with standard errors clustered at the school level. $\mathrm{N}$ corresponds to the number of students that answered each question for the student characteristics and to the number of class for the class and school characteristics. 
Table 4: Outcomes at baseline

\begin{tabular}{|c|c|c|c|c|c|c|c|}
\hline \multirow[b]{2}{*}{ Dependent Variable } & \multicolumn{7}{|c|}{ Determinants } \\
\hline & Mean & St. Dev & Treatment & Female & Low math & Low cognition & $\mathrm{N}$ \\
\hline \multicolumn{8}{|l|}{ Attitudes } \\
\hline Interest & 2.729 & 0.980 & -0.132 & $-0.260^{* *}$ & 0.027 & -0.041 & 757 \\
\hline Self-assessed knowledge & 2.754 & 0.988 & -0.124 & $-0.393^{* * *}$ & -0.118 & 0.015 & 760 \\
\hline \multicolumn{8}{|l|}{ Financial knowledge } \\
\hline At least 1 incorrect answer & 0.608 & 0.489 & -0.045 & 0.0183 & $0.086^{*}$ & -0.060 & 688 \\
\hline Advertising 1 incorrect & 0.164 & 0.371 & -0.033 & -0.021 & $0.101^{* * *}$ & $-0.062^{*}$ & 768 \\
\hline Advertising 2 incorrect & 0.171 & 0.376 & -0.027 & $-0.038^{*}$ & 0.002 & 0.021 & 768 \\
\hline Costs incorrect & 0.255 & 0.436 & 0.023 & 0.042 & 0.045 & -0.043 & 768 \\
\hline Risk incorrect & 0.219 & 0.414 & -0.028 & -0.026 & -0.003 & 0.044 & 688 \\
\hline \multicolumn{8}{|l|}{ Financial behavior } \\
\hline Impulse shop & 0.475 & 0.500 & 0.002 & 0.003 & 0.016 & 0.050 & 768 \\
\hline Just enough money & 0.224 & 0.418 & 0.010 & $0.105^{* * *}$ & 0.020 & -0.004 & 744 \\
\hline Saving $(\mathrm{Y} / \mathrm{N})$ & 0.581 & 0.494 & -0.032 & $-0.099^{* * *}$ & -0.054 & 0.045 & 755 \\
\hline $\ln$ (savings) & 1.997 & 1.959 & -0.142 & $-0.469^{* *}$ & -0.249 & 0.168 & 713 \\
\hline Hypoth. Savings (\%) & 0.213 & 0.230 & -0.029 & $-0.034^{* *}$ & -0.007 & -0.006 & 756 \\
\hline
\end{tabular}

Note: this table reports the mean and standard deviation of the outcome variables at baseline under columns Mean and St. Dev. Each row displays a different outcome variable as defined in Table 2, and one additional variable At least 1 incorrect answer, which takes value 1 if the student answered incorrectly one or more of the financial knowledge questions. The table also reports the coefficient estimates for the variables Treatment, Female, Low math and low cognition, stemming from a separate regression on each outcome at baseline. OLS estimates are presented and each regression included the following additional control variables: school grade, single parents, log of household size, German as a main spoken language at home, number of books in the household (dummy for each category: 0-10 (omitted),11-25,26-100,101-200,201+), and state (dummy for each state). Robust standard errors, clustered at the school level were estimated, ${ }^{* * *} \mathrm{p}<0.01,{ }^{* *} \mathrm{p}<0.05$, $* \mathrm{p}<0.1$. 
Table 5: The effect of the financial education program on attitudes towards finance

\begin{tabular}{lrr}
\hline \hline & $(1)$ & $(2)$ \\
& Interest in finance & Self-assessed knowledge \\
\hline \multirow{2}{*}{ Treatment*Post } & $0.570^{* * *}$ & $0.610^{* * *}$ \\
& {$[0.127]$} & {$[0.132]$} \\
Post & $-0.217^{* *}$ & -0.0444 \\
& {$[0.0982]$} & {$[0.105]$} \\
Treatment & $-0.201^{*}$ & -0.192 \\
& {$[0.102]$} & {$[0.127]$} \\
Girl & $-0.278^{* * *}$ & $-0.299^{* * *}$ \\
& {$[0.0559]$} & {$[0.0411]$} \\
Math low & -0.0195 & -0.109 \\
& {$[0.101]$} & {$[0.0938]$} \\
Cognition low & -0.0637 & 0.0496 \\
& {$[0.0630]$} & {$[0.0507]$} \\
Constant & $2.955^{* * *}$ & $2.774^{* * *}$ \\
& {$[0.310]$} & {$[0.364]$} \\
\hline Observations & 1,298 & 1,299 \\
R-squared & 0.062 & 0.103 \\
\hline \hline
\end{tabular}

Note: this table reports the coefficient estimates for difference-in-difference regression on attitudes towards finance (interest in column (1) and self-assessed knowledge in column (2)). Each regression included the following additional control variables: school grade, single parents, log of household size, German as a main spoken language at home, number of books in the household (dummy for each category: 0-10 (omitted),1125,26-100,101-200,201+), and state fixed effects. OLS robust standard errors, clustered at the school level were estimated and are presented in brackets, ${ }^{* * *} \mathrm{p}<0.01,{ }^{* *} \mathrm{p}<0.05,{ }^{*} \mathrm{p}<0.1$. 
Table 6: The effect of the financial education program on financial knowledge

\begin{tabular}{|c|c|c|c|c|c|}
\hline & $\begin{array}{c}(1) \\
\text { All answers } \\
\text { correct }\end{array}$ & $\begin{array}{c}\text { (2) } \\
\text { Advertising } 1 \\
\text { correct }\end{array}$ & $\begin{array}{c}(3) \\
\text { Advertising } 2 \\
\text { correct }\end{array}$ & $\begin{array}{c}(4) \\
\text { Costs } \\
\text { correct }\end{array}$ & $\begin{array}{c}(5) \\
\text { Risk } \\
\text { correct }\end{array}$ \\
\hline \multirow[t]{2}{*}{ Treatment*Post } & $0.0659^{*}$ & 0.0103 & -0.0489 & 0.0117 & $0.116^{* *}$ \\
\hline & [0.0380] & [0.0314] & [0.0508] & [0.0748] & [0.0570] \\
\hline \multirow[t]{2}{*}{ Post } & 0.00455 & 0.0284 & -0.0162 & 0.0396 & -0.0608 \\
\hline & [0.0162] & {$[0.0257]$} & [0.0380] & [0.0680] & [0.0473] \\
\hline \multirow[t]{2}{*}{ Treatment } & 0.0290 & 0.0272 & 0.0217 & -0.0335 & 0.0188 \\
\hline & [0.0357] & [0.0316] & [0.0373] & [0.0564] & [0.0384] \\
\hline \multirow[t]{2}{*}{ Girl } & 0.0340 & 0.0204 & $0.0456^{* *}$ & -0.00111 & 0.0406 \\
\hline & [0.0365] & [0.0209] & [0.0218] & [0.0220] & [0.0284] \\
\hline \multirow[t]{2}{*}{ Math low } & $-0.0746^{*}$ & $-0.0681^{* * *}$ & -0.0289 & $-0.0582^{* *}$ & 0.00745 \\
\hline & [0.0363] & [0.0213] & [0.0250] & [0.0248] & [0.0289] \\
\hline \multirow[t]{2}{*}{ Cognition low } & 0.0408 & 0.0223 & -0.0150 & $0.0536^{* *}$ & 0.00284 \\
\hline & {$[0.0246]$} & {$[0.0217]$} & [0.0234] & [0.0225] & [0.0275] \\
\hline \multirow[t]{2}{*}{ Constant } & $0.311^{* *}$ & $0.677^{* * *}$ & $0.910^{* * *}$ & $0.737^{* * *}$ & $0.582^{* * *}$ \\
\hline & {$[0.131]$} & {$[0.112]$} & {$[0.119]$} & [0.149] & {$[0.120]$} \\
\hline Observation & 1,204 & 1,303 & 1,303 & 1,303 & 1,196 \\
\hline R-squared & 0.027 & 0.040 & 0.026 & 0.049 & 0.054 \\
\hline
\end{tabular}

Note: this table reports the coefficient estimates for difference-in-difference regression on tested financial knowledge. Each regression included additional control variables, as reported in Table 5. OLS robust standard errors, clustered at the school level were estimated and are presented in brackets, ${ }^{* * *} \mathrm{p}<0.01,{ }^{* *}$ $\mathrm{p}<0.05,{ }^{*} \mathrm{p}<0.1$.

Table 7: The effect of the financial education program on financial behavior

\begin{tabular}{lrrrrr}
\hline \hline & \multicolumn{1}{c}{$(1)$} & \multicolumn{1}{c}{$(2)$} & \multicolumn{1}{c}{$(4)$} & \multicolumn{1}{c}{$(5)$} \\
& Impulse shop & Just enough money & Saving & $\ln ($ saving $)$ & Hypoth. Savings \\
\hline Treatment*Post & $-0.0981^{*}$ & 0.0301 & 0.0546 & 0.278 & 0.0152 \\
& {$[0.0487]$} & {$[0.0656]$} & {$[0.0683]$} & {$[0.350]$} & {$[0.0227]$} \\
Post & 0.0267 & -0.0351 & -0.00557 & -0.108 & 0.0203 \\
& {$[0.0348]$} & {$[0.0504]$} & {$[0.0601]$} & {$[0.330]$} & {$[0.0180]$} \\
Treatment & -0.0110 & 0.0126 & -0.0479 & -0.194 & -0.0374 \\
& {$[0.0526]$} & {$[0.0355]$} & {$[0.0428]$} & {$[0.208]$} & {$[0.0275]$} \\
Girl & 0.0114 & $0.0613^{* *}$ & $-0.0835^{* *}$ & $-0.425^{* * *}$ & $-0.0416^{* *}$ \\
& {$[0.0200]$} & {$[0.0275]$} & {$[0.0293]$} & {$[0.131]$} & {$[0.0151]$} \\
Math low & $0.0499^{* *}$ & 0.0318 & $-0.0466^{*}$ & $-0.219^{*}$ & -0.0183 \\
& {$[0.0203]$} & {$[0.0273]$} & {$[0.0260]$} & {$[0.121]$} & {$[0.0191]$} \\
Cognition low & 0.0201 & 0.00105 & 0.0224 & 0.0697 & -0.00499 \\
& {$[0.0292]$} & {$[0.0225]$} & {$[0.0347]$} & {$[0.127]$} & {$[0.0154]$} \\
Constant & $0.372^{* * *}$ & $0.359^{* * *}$ & $0.416^{* * *}$ & $1.520^{* *}$ & $0.249^{* *}$ \\
& {$[0.130]$} & {$[0.0920]$} & {$[0.142]$} & {$[0.540]$} & {$[0.0879]$} \\
\hline Observations & 1,312 & 1,274 & 1,294 & 1,226 & 1,286 \\
R-squared & 0.030 & 0.032 & 0.051 & 0.042 & 0.058 \\
\hline
\end{tabular}

Note: this table reports the coefficient estimates for difference-in-difference regression on financial behavior. Each regression included additional control variables, as reported in Table 5. OLS robust standard errors, clustered at the school level were estimated and are presented in brackets, ${ }^{* * *} \mathrm{p}<0.01,{ }^{* *} \mathrm{p}<0.05,{ }^{*} \mathrm{p}<0.1$. 


\section{Appendix A}

In this appendix, we present some corroborative evidence. Tables A.1 to A.3 present the results of a simple differen estimator with clustered standard errors for financial interest and self-rated motivation, assessed financial knowledge and finally behavior. These estimates are valid if assignment to training is exogenous. We find similar results as in Tables 5 to 7 which report the results of the difference-in-difference estimator. Financial motivation and selfassessed knowledge are significantly higher among those teenagers who receive the training. Effect sizes are slightly more moderate here but otherwise similar.

We also find similar qualitative results for our measures of financial knowledge: overall knowledge - measured as the sum of correct answers - increases with training, and students' risk assessments improve. Finally, we find that our result on impulse shopping is robust: trained students' frequency of impulse shopping reduces.

As a further robustness check, we also performed propensity score matching which accounts for potential selection on observables if assignment is not at random (Becker and Ichino, 2002). We perform Kernel matching with an Epanechikov kernel and a bandwidth of 0.06. Standard errors are bootstrapped using 50 replications. Balancing conditions are satisfied. The matched sample is balanced based on sex, household size, family background (dummy for single parent family), numeracy score (math grade), cognitive ability, and language spoken at home.

We obtain estimates in the same order of magnitude for financial interest and selfassessed knowledge (Table A.4). Due to the resulting loss in sample size, the results are less precisely estimated, so that we do not find a significant impact on impulse shopping and overall financial knowledge. However, our estimates are very similar for students' risk assessment. 


\section{Figures and tables for Appendix A}

Table A.1: The effect of the financial education program on attitudes - simple differences

\begin{tabular}{lrr}
\hline \hline & $(1)$ & $(2)$ \\
& Interest in finance & Self-assessed knowledge \\
\hline Post & $0.356^{* * *}$ & $0.565^{* * *}$ \\
& {$[0.0969]$} & {$[0.0756]$} \\
Female & $-0.286^{* * *}$ & $-0.299^{* * *}$ \\
& {$[0.0699]$} & {$[0.0439]$} \\
Math low & -0.0106 & -0.0469 \\
& {$[0.127]$} & {$[0.107]$} \\
Cognition low & -0.0772 & -0.0176 \\
& {$[0.0709]$} & {$[0.0519]$} \\
Constant & $2.480^{* * *}$ & $2.042^{* * *}$ \\
& {$[0.515]$} & {$[0.529]$} \\
\hline Observations & 1,027 & 1,027 \\
R-squared & 0.073 & 0.12 \\
\hline \hline
\end{tabular}

Note: this table reports the coefficient estimates for a simple differences regression on attitudes towards finance. Each regression included additional control variables, as reported in Table 5 in the main text. OLS robust standard errors, clustered at the school level were estimated and are presented in brackets, *** $\mathrm{p}<0.01,{ }^{* *} \mathrm{p}<0.05,{ }^{*} \mathrm{p}<0.1$.

Table A.2: The effect of the financial education program on financial knowledge - simple differences

\begin{tabular}{lrrrrr}
\hline \hline & $\begin{array}{c}(1) \\
\text { All answers } \\
\text { correct }\end{array}$ & $\begin{array}{c}\text { Advertising 1 } \\
\text { correct }\end{array}$ & $\begin{array}{c}\text { Advertising 2 } \\
\text { correct }\end{array}$ & $\begin{array}{c}\text { Costs } \\
\text { correct }\end{array}$ & \multicolumn{1}{c}{$\begin{array}{c}\text { Risk } \\
\text { correct }\end{array}$} \\
\hline Post & $0.0696^{*}$ & $0.0397^{*}$ & $-0.0694^{*}$ & 0.0507 & $0.0564^{*}$ \\
Female & {$[0.0353]$} & {$[0.0202]$} & {$[0.0348]$} & {$[0.0313]$} & {$[0.0325]$} \\
& 0.0215 & 0.013 & $0.0387^{*}$ & -0.00261 & 0.0454 \\
Math low & {$[0.0438]$} & {$[0.0225]$} & {$[0.0228]$} & {$[0.0257]$} & {$[0.0286]$} \\
& -0.0572 & $-0.0769^{* * *}$ & -0.0424 & $-0.0431^{*}$ & 0.0165 \\
Cognition low & {$[0.0444]$} & {$[0.0254]$} & {$[0.0290]$} & {$[0.0251]$} & {$[0.0342]$} \\
& 0.0324 & -0.00341 & -0.0282 & $0.0587^{* *}$ & 0.0127 \\
Constant & {$[0.0283]$} & {$[0.0215]$} & {$[0.0281]$} & {$[0.0246]$} & {$[0.0324]$} \\
& $0.337^{*}$ & $0.677^{* * *}$ & $0.822^{* * *}$ & $0.625^{* * *}$ & $0.807^{* * *}$ \\
& {$[0.162]$} & {$[0.132]$} & {$[0.153]$} & {$[0.152]$} & {$[0.149]$} \\
\hline Observations & 950 & 1,030 & 1,030 & 1,030 & 942 \\
R-squared & 0.024 & 0.041 & 0.03 & 0.046 & 0.058 \\
\hline \hline
\end{tabular}

Note: this table reports the coefficient estimates for a simple differences regression on tested knowledge about finance. Each regression included additional control variables, as reported in Table 5 in the main text. OLS robust standard errors, clustered at the school level were estimated and are presented in brackets, ${ }^{* * *}$ $\mathrm{p}<0.01,{ }^{* *} \mathrm{p}<0.05,{ }^{*} \mathrm{p}<0.1$. 
Table A.3: The effect of the financial education program on financial behavior - simple differences

\begin{tabular}{lrrrrr}
\hline \hline & $(1)$ & $(2)$ & $(3)$ & $(4)$ & $(5)$ \\
& Impulse shop & Just enough money & Saving & $\ln ($ saving) & Hypoth. Savings \\
\hline Post & $-0.0671^{*}$ & -0.00714 & 0.0455 & 0.159 & $0.0318^{* * *}$ \\
& {$[0.0359]$} & {$[0.0387]$} & {$[0.0290]$} & {$[0.110]$} & {$[0.0104]$} \\
Female & -0.0134 & $0.0591^{*}$ & $-0.0864^{* *}$ & $-0.433^{* *}$ & $-0.0359^{* *}$ \\
& {$[0.0211]$} & {$[0.0281]$} & {$[0.0347]$} & {$[0.159]$} & {$[0.0162]$} \\
Math low & $0.0516^{* *}$ & 0.0265 & $-0.0599^{* *}$ & $-0.296^{* *}$ & -0.0187 \\
& {$[0.0239]$} & {$[0.0330]$} & {$[0.0234]$} & {$[0.113]$} & {$[0.0232]$} \\
Cognition low & 0.00786 & 0.00601 & 0.0186 & 0.00285 & -0.00715 \\
& {$[0.0338]$} & {$[0.0286]$} & {$[0.0388]$} & {$[0.133]$} & {$[0.0160]$} \\
Constant & 0.362 & $0.248^{*}$ & 0.271 & 1.231 & 0.0425 \\
& {$[0.245]$} & {$[0.134]$} & {$[0.186]$} & {$[0.737]$} & {$[0.0691]$} \\
\hline Observations & 1,039 & 1,009 & 1,027 & 973 & 1,016 \\
R-squared & 0.036 & 0.032 & 0.059 & 0.052 & 0.076 \\
\hline \hline
\end{tabular}

Note: this table reports the coefficient estimates for a simple differences regression on financial behavior. Each regression included additional control variables, as reported in Table 5 in the main text. OLS robust standard errors, clustered at the school level were estimated and are presented in brackets, ${ }^{* * *} \mathrm{p}<0.01,{ }^{* *}$ $\mathrm{p}<0.05,{ }^{*} \mathrm{p}<0.1$.

Table A.4: Propensity score matching results

\begin{tabular}{lrrr}
\hline \hline & \multicolumn{2}{c}{ Average treatment effect on the treated } \\
\hline & ATT & Std. Err. & t-value \\
\hline Interest in finance & 0.351 & 0.103 & 3.399 \\
Self-assessed knowledge & 0.408 & 0.118 & 3.466 \\
\hline All answers correct & 0.077 & 0.049 & 1.578 \\
Advertising 1 correct & 0.015 & 0.052 & 0.28 \\
Advertising 2 correct & 0.046 & 0.031 & 1.512 \\
Costs correct & 0.003 & 0.032 & 0.084 \\
Risk correct & 0.132 & 0.05 & 2.644 \\
\hline Impulse shop. & -0.049 & 0.046 & 1.073 \\
Just enough money & 0.047 & 0.044 & 1.06 \\
Saving & 0.003 & 0.065 & 0.052 \\
$\ln$ Saving) & 0.076 & 0.189 & 0.403 \\
Hypoth. Saving & -0.02 & 0.029 & 0.672 \\
\hline \hline
\end{tabular}

Note:Estimation using Kernel matching with an epanechikov kernel, 0.06 bandwidth and bootstrapped standard errors (with 50 replications). Balancing conditions are satisfied. The matched sample is balanced based on sex, household size, family background (dummy for single parent family), numeracy score (math grade), cognitive ability, and language spoken at home. We are applying the estimation tools discussed in Becker and Ichino(2002) 


\title{
Appendix B
}

We provide a brief description of the trainings provided by My Finance Coach as well as a translated version of the questionnaire in what follows.

\section{The Training Modules offered by My Finance Coach}

\author{
A Summary and Relation to Survey
}

\section{Shopping Module}

The module first addresses the distinction between needs and wants and encourages children to (1) reflect on what they really need and distinguish it from what they want, and (2) prioritise their spending by buying first what they really need. It then discusses the places where advertising is found, the instruments it uses and the typical messages in ads. Then it moves to the discussion about how to decide which cell phone or smart phone to buy. Students participate in a role-play, where Paul wants to buy a new phone and discusses it with his parents and friends.

Relation to our survey questions: The question about impulse purchases and the questions on advertising relate to this training.

\section{Planning Module}

The module first addresses the definition of a plan and shows different examples. It then defines the concepts of income and expenses, using practical examples, and shows students can make plans about income and expenses. The students go through a case study in which Felix decides whether to buy a moped or not. They discuss potential costs of a moped and are shown the distinction between costs that are incurred once and running costs. They are then asked to reflect on which strategies Felix could use to be able to afford the moped: increase income, reduce expenses or take on debt. Taking debt is not recommended to students. Students are then suggested to use plans for their own goals.

Relation to our survey questions: The smartphone question relates to this module.

\section{Saving Module}

The module first addresses the definition of savings and describes a variety of savings products. Then, savings motives are discussed.. The training introduces the concept of magic triangle, which exposes the trade-off between risk, return and liquidity. Students participate in a role-play in which they discuss the adequacy of different savings products for a hypothetical person Paul's savings goal, to save 1.500 Euro for his driver's license test in 4 years. Students are then advised not to believe a product can offer everything: high return, liquidity and safety, and to critically assess financial offers made to them.

Relation to our survey questions: The question about the least liquid asset relates to this module 


\section{You and your finances}

\section{Questionnaire}

Prof. Dr. Joachim Winter and Dr. Marta Serra-Garcia (LMU Munich) and

Dr. Melanie Luhrmann (Royal Holloway, University of London)

in cooperation with My Finance Coach

Spring/Summer 2012 
We are conducting a scientific study into teenagers' financial knowledge and financial decisions and would like to ask a few questions on these topics.

Your responses to this survey will not have any consequences for you. The responsibility for compliance with data protection regulations lies with Prof. Dr. Joachim Winter at the LudwigMaximilians-University Munich. A detailed explanation of these regulations can be found at the end of this questionnaire.

For data protection reasons, we do not want to ask you for your name. Thus, we use the following three questions to link your answers - similar to a bank accounts' pin code -, since we will ask you to participate in a survey again in a few weeks.

F1. What is the first letter of your mother's first name?

F2. What is the first letter of your surname?

F3. What is your street number? (Please fill in all digits, e.g. "7" or "143")

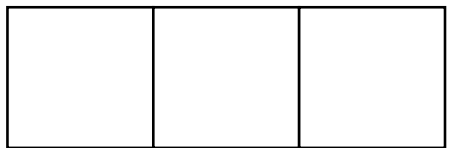

F1 $\quad$ F2 $\quad$ F3 


\section{Your money and your personal finances}

Please circle the item that represents your opinion best.

Q1. "To deal with financial matters..."

is no fun

\begin{tabular}{|l|l|l|l|l|}
\hline 1 & 2 & 3 & 4 & 5 \\
\hline
\end{tabular}

is great fun

Q2. "In money and financial matters, I am..."

badly versed

\begin{tabular}{|l|l|l|l|l|}
\hline 1 & 2 & 3 & 4 & 5
\end{tabular}$\quad$ very well versed

Q3. "I often buy spontaneously, what I like to have."

Strongly disagree

\begin{tabular}{|l|l|l|l|l|}
\hline 1 & 2 & 3 & 4 & 5 \\
\hline
\end{tabular}

strongly agree

Q4. "Advertising intends to inform me about the best products."

Strongly disagree

\begin{tabular}{|l|l|l|l|l|}
\hline 1 & 2 & 3 & 4 & 5 \\
\hline
\end{tabular}

strongly agree

Q5. "Advertising intends to sell me something."

Strongly disagree

\begin{tabular}{|l|l|l|l|l|}
\hline 1 & 2 & 3 & 4 & 5 \\
\hline
\end{tabular}

strongly agree

Q6. "Advertising wants to show me what I need."

Strongly disagree

\begin{tabular}{|l|l|l|l|l|}
\hline 1 & 2 & 3 & 4 & 5 \\
\hline
\end{tabular}

strongly agree

Q7. "What happens if you buy a smartphone (e.g. iPhone)?

"When I buy a smartphone, I will have costs (price of the smartphone) only once."

Strongly disagree

\begin{tabular}{|l|l|l|l|l|}
\hline 1 & 2 & 3 & 4 & 5 \\
\hline
\end{tabular}

strongly agree

"When I buy a smartphone, I will have costs several times as long as I still own it."

Strongly disagree

\begin{tabular}{|l|l|l|l|l|}
\hline 1 & 2 & 3 & 4 & 5 \\
\hline
\end{tabular}

strongly agree 
Q8. Christina wants to invest money and take as little risk as possible. Which of the following investments would you recommend? (Please tick only one box)

$\square$ Call money

Real estate

A share which makes her a co-owner of a company

Q9. Do you receive pocket money?

No

Yes, Euro per week

(If you receive pocket money on a monthly basis, you have to divide the amount by 4, if you receive it every 2 weeks, please divide it by 2.)

Q10. How much other money did you receive in the last 4 weeks, e.g. from parents, friends or relatives? Was it a gift or did you borrow it?

Gift: _ Euro

Borrowed Amount: __ Euro

Q11. Sometimes students cannot make ends meet with their weekly allowance or income. How was it for you last week?

I had some money left at the end of the week.

I had just enough money for the whole week.

I ran out of money during the week.

I coped with this by

O borrowing money

O not spending any money

O withdrawing some savings

Q12. Are you currently in debt?

Yes, how much? Euro

No

Q13. If you do casual jobs, how much money did you earn in the last four weeks? Euro.

Q14. Did you receive income from another source (not mentioned above) in the last four weeks?

$\square$ Yes, how much? Euro

$\square$ No 
Q15. Do you have a savings account?

$\square$ Yes

No

Q16. Can you withdraw money from this account without your parents' (legal guardian's) permission?

$\square$ Yes

No

Q17. Did you save in the last four weeks?

No

Yes Euro

Q18. Why do you save? (Check all applicable boxes)

I want to buy a specific item.

I want to put money aside for emergencies.

I save for the future.

I do not save.

Q19. Imagine you have 100 Euro available in the next month but no other income. How do you allocate the money to the following? Please allocate the money so that you spend exactly 100 Euro.

Savings

Food and drinks

Transport (for example bus or train)

Leisure (going out, cinema, concerts)

Clothes, shoes and/or cosmetics

Magazines and books

Computer games and internet

Mobile phones

Sweets

Ringtones/music downloads

Other
Euro

Euro

Euro

Euro

Euro

Euro

Euro

Euro

Euro

Euro

Euro

Q20. And last: How much money did you spend last week?

Euro 


\section{Your personal details}

This section contains questions about you and your family. If you live in more than one family, please answer the following questions with respect to the family with whom you spend most of the time.

Q21. When were you born?

Month

Year

Q22. What is your gender?

Female

Male

Q23. Who lives with you most of the time? (Tick all applicable boxes)

Your mother (also stepmother or foster mother)

Your father (also stepfather or foster father)

Your siblings (also stepsiblings); how many?

Other persons (e.g. cousin, grandmother, grandfather); how many?

Q24. Which is the main language you use at home? (Please tick only one box)

German

Other language

Q25. How many books do you have at home?

A bookshelf with a length of one meter stores around 40 books. Please do not list magazines, newspapers and your schoolbooks. (Please tick only one box.)
$\square$
$0-10$ books
101-200 books
$11-25$ books
201-500 books
26-100 books
$\square$ more than 500 books

Q26. Financial planning has something to do with math. Which overall math grade did you receive last year?

Maths-grade

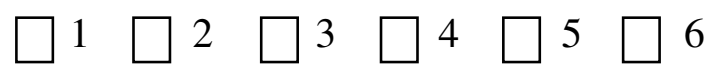

\section{Questions on My Finance Coach}

Q27. Did you ever visit the website of My Finance Coach?

\begin{tabular}{ll}
$\square$ & Yes \\
\hline$\square$ & No
\end{tabular} 


\section{Combinations}

Financial planning has something to do with combination skills. We would like to test your combination skills through four short questions. Please take a look at one picture after the other. Which of the pieces in the lower area completes the pattern in the upper area? Please circle it.

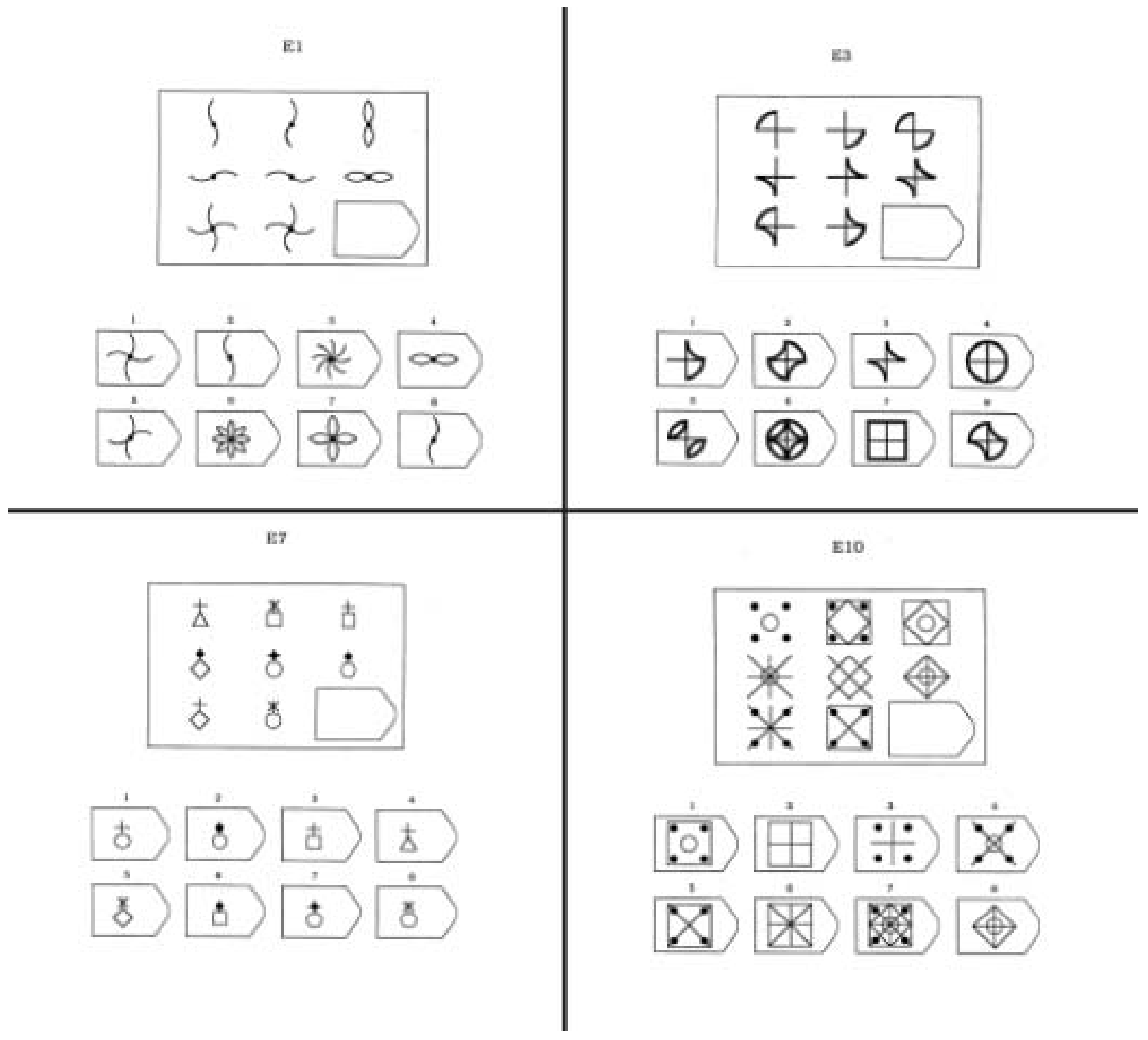




\section{Notes on the questionnaire}

We will never ask you for your name or your address. We pursue no financial interest with this survey. It is conducted only for scientific purposes. We will question you again in around one month. For this reason, we ask you three questions in the beginning, which help us to link your answers from both questionnaires using a code-number, which you generate yourself.

Your data will be gathered by researchers from the Ludwig-Maximilians-University Munich. Then, it will be saved electronically, analyzed and safely stored. Your data will be saved only for as long as is necessary for the scientific analysis and subsequent publication process. It will not be shared with third parties and will be deleted after publishing of the findings. The results, which will be published, do not allow the tracing of information of any individual. 